\title{
Perspectives on Resilience to Disasters across Sectors and Cultures
}

\author{
Brian Walker $^{1}$ and Frances Westley ${ }^{2}$
}

\begin{abstract}
We present some insights on the use and interpretation of resilience ideas that arose in a conference on "Society's Resilience in Withstanding Disaster." Three points in particular have relevance for those interested in resilience in social-ecological systems: (1) Time as a threshold vs. avoiding quick fixes; (2) Trading risks: specified vs. general resilience; (3) Response origination: building local general resilience, and general resilience in central agencies. In the latter the need is to allow improvisation, and failure, during times of crisis.
\end{abstract}

Key Words: disasters; resilience; risk

\section{INTRODUCTION}

This paper was stimulated by our participation in a Ditchley Foundation conference on Society's Resilience in Withstanding Disaster, in March 2009 (http://www.ditchley.co.uk/page/343/societys-resilience.

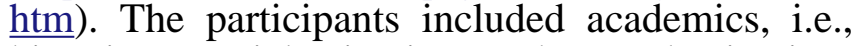
historians, social scientists, and natural scientists, politicians, bureaucrats, representatives of NGOs, and people involved in international disaster programs. Though terrorism was a strong focus it was not the only one and is, in fact, a rather special case.

We write this from the perspective of a group, The Resilience Alliance, involved in the dynamics of linked social-ecological systems and, as an initial observation, the notion of discontinuous change and alternate stable states, a cornerstone of an ecological view of resilience, was not familiar to most of the participants. The general idea of tipping points and loosely or nondefined thresholds, however, was common. The following three paradoxes struck us as worthy of more consideration in cross-sector discussions and analyses.

\section{TIME AS A THRESHOLD VS. AVOIDING QUICK FIXES}

Time as threshold: speed of return does matter

In ecology speed of return of a system when disturbed from its equilibrium (the engineering definition, cf Holling 1996) is of interest in studies of population dynamics, but because the metrics for measuring it only hold in the neighborhood of the equilibrium value it has not been of much interest to those concerned with threshold effects, i.e., how much a system can be changed and still be able to recover. Two aspects of time following a disaster emerged in the meeting as being of great importance. First, there was general agreement that the longer a community or society stays in a disturbed state after a disaster the more difficult it becomes for that community to recover, and eventually it may not be able to recover. Being in a disturbed state erodes capacity to organize and respond, and induces new feedbacks that tend to keep the system in the disturbed state. This effect can be amplified where there are people who benefit from being in the disturbed state and attempt to keep it there. Therefore, length of time in a disturbed state may itself be a variable with a threshold. 


\section{Avoiding quick fixes}

In contrast, in some situations a short-term, e.g., three day, response is not sufficient to trigger recovery because the problem is too complex to engage in that period of time. In such situations the short-term, quick intervention that seemed to be the preferred type of response to disasters might in fact be causing a kind of peripheral blindness, a preference to focus on only those disasters that are conducive to a quick response and a tendency to declare victory, as George W. Bush did in the Iraq war, on a superficial basis. Meanwhile the longer term vulnerabilities that result from disasters are ignored, passed over to other services and agencies, and are never measured when considering whether the disaster response was adequate. In a sense, in these situations the costs are externalized or displaced away from disaster relief agencies onto other social service agencies. Therefore, from an accounting perspective, although the specific resilience of the system to the immediate disaster may appear to have been addressed the general resilience of the system may be decreased, making it more vulnerable to future shocks. An example is the victims of Katrina who were exported to other parts of the U.S. where the social service agencies did not receive longer term disaster funding to deal with their needs as displaced people. In socialecological systems this quick fix problem is analogous to building resilience in the focal system and thereby causing it to decline in the broader system.

As a final comment on timing the above discussion assumes the system was in a desirable state before the disaster. Where it is not the disaster can provide the opportunity for change, a kind of reset button that allows changes that were not feasible in normal times; the pity-to-waste-a-good-crisis idea. However, unless there is specific preparation of alternative scenarios there is less likelihood that a reset will occur.

\section{TRADING RISKS: SPECIFIED VS. GENERAL RESILIENCE}

It was observed by many participants that if you push a problem down in one place it will pop up in another, usually unpredictable, place, a phenomenon labeled by one participant as Murphy's water bed.
The military participants considered that it is often better to leave a potential problem where you can keep an eye on it, though it is necessary to be able to respond to unexpected issues in unexpected places. This is related to the notion of specified and general resilience and the highly optimized tolerance (HOT) proposition of Doyle and colleagues (Carlson and Doyle 2000), which states that the more robust you make a system in one way, necessarily the less robust it becomes in others. This inevitable trade-off suggests we should be organizing resources to expect the unexpected and building general resilience. However, preparedness for disaster tends to follow particular risk calculations. Severity of disasters and hence the risk associated with different kinds of disasters is measured in terms of individual mortality, with greater resources, quicker response, and more planning associated with higher risk assessments. From the political perspective risk assessment becomes a highly political process of claiming which percentage is associated with which risk, privileging specified over general resilience. The key question we felt should not be what is the proportional risk associated with which threats, but which disasters were more likely to reduce overall resilience of the system. Preparedness for and response to particular disasters involves clearly defined players and is much easier to plan for and implement than trying to avoid unspecified disasters, i.e., risk reduction. The latter is much more wide ranging and difficult yet it is most needed, in the opinion of the group. The cost of not maintaining general resilience is much harder to estimate and the cost of doing so harder to justify. This results in a tendency to focus on outputs that can be measured, as opposed to outcomes that are longer term involving complex interactions, and less easy to measure.

\section{RESPONSE ORIGINATION: LOCAL VS. CENTRALIZED}

Discussion of accountability led to consideration of where responses to disasters should best originate. Participants viewed the greatest threat as originating from the highly interconnected nature of our communication system and economies but, although consistent with resilience perspectives, there was little discussion of the fact that government institutions at any level were rarely 
interconnected except to note the amount of jealousy, turf issues, and struggles for resources that characterized coordination attempts. However, government representatives who were present expressed the need to push power up to the international level, in an attempt to anticipate and provide adequate response to threats such as terrorism, which seemed to have a truly global dynamic, but at the same time to push power down to the local community level where sense-making, self-organization, and leadership in the face of disaster were more likely to occur if local governments felt accountable for their own responses. One discussion framed the need in terms of promoting the philosophies of both Hobbes, i.e., a social contract ceding freedoms to a higher authority, and Rousseau, i.e., look for the good in people to develop personal responsibility from the bottom up. This is reflected in the social-ecological resilience literature on the need at local scales for adaptive governance and comanagement, and at higher scales for global scale institutions in the face of looming global scale failures (as articulated in a recent Science article, Walker et al. 2009). Current efforts and emphases are focused too much at the levels in between.

This brought to mind the notion that for general resilience we need both top-down and bottom-up institutions. For dealing with disasters society needs both. This corresponds with the conclusions of $\mathrm{E}$. Ostrom and colleagues (e.g., Dietz et al. 2003) on the need for both in common property adaptive governance institutions. However, barriers to adaptation are different at the two scales as Ditchley discussions revealed. In particular, from a resilience perspective the mechanisms for building social learning and memory were identified as different.

\section{Building local general resilience}

There was considerable discussion about building local resilience and some interesting evidence presented that exercises such as simulations help considerably in this regard. We came to see such rehearsals for disaster preparedness as the equivalent of probing the boundaries of resilience. Conducting evacuation exercises, for example, not only identifies particular areas that need addressing to improve response capacity, but the exercise itself increases community collaboration, communication, and identity and therefore response capacity. This is related to the need for sense-making and social memory in situations of disaster. Response is slowed by the disorder of breakdown and requires framing, often by particular leaders, to ignite action. Rehearsals and exercises provide an opportunity for making sense in advance of the actual disaster, which allows for better response and triggers selforganizing capacities. In effect, this is a kind of storytelling that builds a repertoire of alternative scripts. It appeared that exercises and rehearsals also triggered memory and social learning which at times produced more scripts as alternative responses.

\section{Building general resilience in central agencies}

As noted above, the need for speed in times of crisis can reduce general resilience by privileging specific resilience. It can also reduce the capacity for learning which is key for transforming short-term disaster into longer term resilience. In emergency operations responses are by definition highly specific and formal, with little room to improvise. There is also a general tendency with consequent expenditure of effort to assign blame, and failure to follow the prescribed formula can result in having to accept an undue proportion of that blame. However, by definition, if disasters are unexpected improvisation, a kind of in the moment experimentation, may be essential and the capacity to share such rule breaking can allow for deep learning and innovation in the central agencies responsible for disaster relief. Creating such a safe space for a temporary suspension of rules and of accountability assessment is challenging but can be transformative. One fascinating comment in regard to how the breakthrough was made around Northern Ireland peace negotiations was that a consensus was achieved in one meeting that peace was more important than justice. Unless such rule free zones are temporarily invoked the tendency is to look for blame, which shuts down the capacity to learn from the crisis. Those familiar with the ecosystem dynamics part of social-ecological systems will recognize that it is during times of major disturbance that novelty and experimentation come to the fore. It is in the social part of the system that conservative caution dampens it. The contemporary systems of accountability, although important, must at times be seen as real barriers to resilience. 


\section{CONCLUSIONS}

There are interesting synergies between work on anticipating disasters and work in social-ecological resilience. The disaster work sheds light on the difficult role of government agencies in disaster mediation, the problematic role of accountability, the importance of time, i.e., not too long (time as a threshold) and not too soon (quick-fix failures), in achieving an adequate response, and the importance of sense-making capacities at the community level. Resilience thinking can inform disaster studies by its capacity to see normal times and times of disaster and collapse as different phases of the same system, and the appreciation of controlling (slow) variables as an important and overlooked part of most risk assessment. Resilience theorists can also learn from the many examples experienced by the disaster relief community, and the observations in this paper provide a start for what needs to be a more comprehensive comparative analysis of the two areas of experience and expertise.

Responses to this article can be read online at: http://www.ecologyandsociety.org/voll6/iss2/art4/responses/

\section{Acknowledgments:}

We thank Tom Measham and Tim Lynam for helpful comments and Tim for his suggestions.

\section{LITERATURE CITED}

Carlson, J. M., and J. Doyle. 2000. Highly optimized tolerance: robustness and design in complex systems. Physical Review Letters 84:2529-2532.

Dietz, T., E. Ostrom, and P. C. Stern. 2003. The struggle to govern the commons. Science 302:1907-1912.

Holling, C. S. 1996. Engineering resilience versus ecological resilience. Pages 31-44 in P. C. Schulze, editor. Engineering within Ecological Constraints. National Academy Press, Washington, D.C., USA.
Walker, B., S. Barrett, S. Polasky, V. Galaz, C. Folke, G. Engström, F. Ackerman, K. Arrow, S. Carpenter, K. Chopra, G. Daily, P. Ehrlich, T. Hughes, N. Kautsky, S. Levin, K.-G. Mäler, J. Shogren, J. Vincent, T. Xepapadeas, and A. de Zeeuw. 2009. Looming global-scale failures and missing institutions. Science 325:1345-1346. 